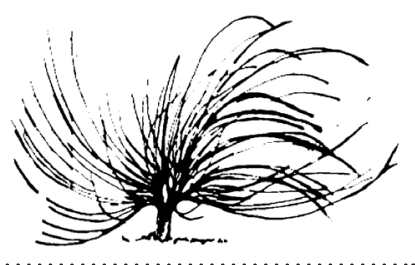

\title{
Educación, comunidad y liberación. Comentarios a partir del pensamiento pedagógico de Paulo Freire y Alejandro Cerletti: aportes a la enseñanza de la filosofía
}

\author{
Juan Rafael Gómez Torres ${ }^{1}$ \\ Universidad Nacional \\ Costa Rica \\ ggomezz1@yahoo.es
}

\begin{abstract}
"En virtud del reconocimiento de la pertinencia política de la educación en la conformación e integración social, y partiendo de él, una de las tareas de la filosofía es identificar sus aspectos cruciales y conceptualizarlos"
\end{abstract}

(Cerletti, 2016, pp. 17-18).

En el siguiente escrito daremos algunos criterios sobre la importancia de lo comunitario como un hecho total social necesario para alcanzar una educación que, además de crítica y rigurosa sea, a su vez, pertinente, significativa y transformadora. Para eso se analizan las propuestas de Paulo Freire y Alejandro Cerletti de problematizar la realidad mediante la emergencia del/de la otro/a, o de aprender mediante nuestras preguntas, considerando a los discentes desde una relación sujetos-sujetos y no como objetos de la educación, quienes desde su realidad y necesidades pueden asumir lo educativo como un proceso de liberación donde la filosofía juega un papel fundamental.

1 Académico de Educología, CIDE, UNA 


\section{La Educación como un acto social total para la enseñanza de la filosofía}

La importancia de la educación como hecho social, como realidad y como fundamento de la comunidad cultural, es indudable. Ante todo, para nuestra región latinoamericana, caracterizada por graves problemas de desigualdad social interna propias de la forma de organización vigente del capitalismo global.

Al respecto, Freire ve a la educación como una realidad humana que puede ser utilizada tanto para la opresión como para la liberación de los pueblos según sea la intencionalidad que se imprima a la misma. Según él, la enseñanza posee un carácter liberador no reducible a la emancipación alfabetizante, o a lo que hoy se le denomina alfabetización funcional, pues en la alfabetización crítica se esconde un potencial de transformación tanto personal como colectiva o comunitaria.

Lo anterior supone descolonizar términos o categorías que resultan banalizadas desde el discurso mercantil, para el cual la pobreza, la desigualdad, el dolor, la tragedia interespecies (Singer, 1999) y ecológica en general, son asuntos de menor importancia, son efectos colaterales de una mejor vida y son ineludibles. Ese discurso hegemónico y sistémico deifica la moral del más fuerte (May, 2004), haciendo de la competencia un lugar "natural" y central para educarse en el mundo presente que es el mundo del mercado; un mundo donde la Pedagogía crítica y la filosofía en general no son bienvenidas o no tienen lugar en tanto pueden y suelen cuestionar su centralismo en la vida humana y total.

Por ello, nos interesa la idea de ver a la educación como hecho social total, como un holom, con el fin de revisar categorías como ética de la vida, de la comunidad y de la liberación más allá de los abstractos de una ética universal y categórica. Esta última implica la obediencia para ser libres, pues para Kant (2012), entre otros éticos deontológicos, la obediencia nos hace libres; el ser un buen ciudadano es lo que nos libera. Para llegar a la educación liberadora se debe romper con esa línea moderna imperial y colonizadora del ser disciplinado y obediente. En cuanto a la enseñanza de la filosofía, esta puede romper con ese mandato moderno si se lanza a la experiencia, a la vida o al caos (Cerletti, 2016), lo que sugiere una revisión radical de su quehacer en el aula y fuera de ella. 
Se podría iniciar con la relación pedagógica entre el docente y el discente: en ella suele establecerse una negación del discente al analogarlo con un infante en su sentido clásico, como un balbuceante, alguien que no es, pero puede llegar a ser solo si se deja completar (Skliar, 2007), por cierto, mediante un currículo en el que tampoco participa como sujeto educativo, uno que establece el grupo hegemónico en el poder y del que se espera sea reproducido sin más por el profesorado con el fin de alcanzar ciudadanos obedientes. En esa relación peyorativa o adultocéntrica, el estudiante solo debe seguir los preceptos del maestro explicador (Rancière, 2003), quien lo completará con el filo-logos europeo (Dussel, 2015), sin tomar en cuenta su origen, contexto, saberes, realidad ni sus emergencias.

\section{Punto de partida: La educación como hecho social total}

Una de las lecciones más importantes de Freire es el reconocimiento meta social de la educación como un hecho social total. ¿Qué quiere decir esto? Nada tan sencillo: traslada a la idea de que la educación es una forma de micromundo, pueblo o comunidad. Esa compleja forma de ser y estar en la educación, evita la fragmentación sistémica propia de la vacuidad actual del sistema educativo lanzado a la repetición del estado actual de las cosas, donde la obediencia es fundamental para reproducir la desigualdad social que le caracteriza.

La educación, por ende, no entendida como sistema educativo, involucra todas las facetas y energías de la vida en su mismo despliegue óntico sin que eso sea un vitalismo en tanto ideología. No se trata de interacciones entre elementos o factores rígidos sino de interacciones entre procesos epistemológicamente ricos en su manera de ser y de existir, irreductibles a una teoría sistémica. No queremos caer tampoco en un espiritualismo postmoderno ni en un populismo epistemológico, sino que, más bien, intentamos visualizar el todo, que ocurre o se materializa detrás de las partes inseparables entre sí, dentro del devenir (Hegel, 2008; Marx, 1981; Heidegger, 2012; Lévinas, 2009; Singer, 2003), pero sin recurrir para ello a la idea de sistema. Nos parece interesante la concepción propia de nuestros pueblos indígenas, para quienes es la armonía del "todo con todo" lo que da sentido a sus vidas, como lo creen los Bribri en Costa Rica. 
La educación compromete desde el todo de la realidad social, porque solo desde esta totalidad en su despliegue es que ocurre nuestra vida y nuestras relaciones con las y los demás. Por ello, en el caso de Freire, la liberación deviene como acto colectivo frente al dolor y la muerte que produce la sujeción (Althusser, 1988; Butler, 1997). La tarea de la educación no es solo una tarea, sino que también se instituye como una forma de vida, como un desplegarse y un salirse de la inmediatez del dominio y del control político, mental, emocional y social, cuestión en la que puede colaborar profundamente la filosofía.

Así, por ejemplo, para los Bribri educarse es aprender historias, escuchar a las/los ancianos, observar al otro para aprender de él o ella, producir solo lo que se necesita, compartir lo que se tiene, comprender el tiempo y el espacio (el $k \underline{a}$ ) como no fijos, movibles o transformables, aceptar la diferencia sin sobresalto, no negar el conflicto ni el error pues ambos son fuente de saber, aunque el quedarse en ellos suele ser negativo, practicar lo enseñado hasta hacerlo parte de su vida. Eso implica estar afuera o salirse de las relaciones de dominación capitalista; supone, a su vez, salirse del orden "sistémico" y reduccionista que hoy en día "mueve" al mundo.

La comunidad educativa supone que, dentro de ella, unos y otros nos veamos en el cara a cara de cada día. Pero no de un cara a cara centrado en el dominio de un tiempo regulado y disciplinado, un tiempo y espacio lleno de no lugares, sino de un cara a cara que rompe la linealidad del tiempo/espacio productivista o secuencial, que ven a la escuela como una especie de fábrica.

\section{Es decir, la educación se constituye desde la ética de la liberación}

Independientemente de los análisis puramente "positivos" sobre la educación, especialmente en nuestra región latinoamericana, que reducen el estudio de la misma a sus condiciones sociales e históricas objetivas, es impensable llegar a alguna posible alternativa crítica o ir más allá de los mismos si no se plantean desde una impronta ética, ligada con las necesidades, las emergencias y el futuro de aquellos que menos tienen o, como afirma Dussel (2015), el compromiso del pensamiento liberador está con las víctimas del sistema capitalista global. 
Dicho con otras palabras, la educación latinoamericana debe responder a dos principios fundamentales: primero las condiciones objetivas ya señaladas sobre esta, que vistas desde una perspectiva crítica y negativa (Dussel, 2015 y Adorno, 1999), nos muestran las gravísimas condiciones sociales y económicas de desigualdad en que están nuestros pueblos; es decir, el mismo análisis de la realidad se instituye como punto de partida de toda crítica del fenómeno educativo como tal. Esa realidad, aunque no resulta suficiente para una comprensión integral del dicho fenómeno, sí constituye el punto de partida de este pensamiento crítico de la educación, lo que nos lleva a la segunda dimensión por acotar, esto es, aquella que se liga con un necesario proceso auto liberador (Freire, 2005) y transgresor de tales condiciones objetivas.

La educación así entendida es un proceso interrelacional, dialéctico y dialógico en contra del sujeto universal, obediente y liberal que, según Žižek (2009), es "capaz de desprenderse de sus raíces particulares culturales/sociales y de afirmar su plena autonomía y su universalidad" (p. 172), sin desdibujar las normas sociales que funcionan como imperativos categóricos (neokantismo), donde se es libre cuando más se obedece.

Ese sentido kantiano de la obediencia sistémica y la disciplina metódica, como ya se apuntó, es el que impera en nuestros sistemas educativos y contra el cual debemos luchar los profesores de la enseñanza de la filosofía, pues genera o legitima la opresión de nuestros pueblos frente a sistemas económicos transnacionales que dictan lo que se debe seguir y enseñar en la educación formal de nuestros países.

\section{Un aporte de Paulo Freire y Alejandro Cerletti a la enseñan- za de la filosofía}

En Freire es indiscutible que la educación o nos libera o nos asesina. Interpretando atrevida y libremente su obra, se puede rastrear su acusación de una educación que es bancaria y otra que propicia la concientización o, como apunta Cerletti en el presente texto, favorece la problematización del acontecimiento, del azar o de lo aleatorio. La primera genera la mecanización del aprendizaje, la segunda nos puede liberar de las cadenas de la opresión mental, colonial, económica, política, estética y ética. Freire recurre a la filosofía para explicar esa doble dimensión política de la educación: acude a Hegel (2008), concretamente a su dialéctica del amo y del esclavo, y a Marx (2008) en su 
materialismo histórico, donde "el modo de producción de la vida material determina [bedingen] el proceso social, político e intelectual de la vida en general" (pp. 4-5). También acude para ello a la sabiduría de los pueblos indígenas, de las comunidades campesinas y los poblados urbano marginalizados de distintas ciudades de América Latina y África. Desde allí hace su propuesta de una pedagogía liberadora.

Sin embargo, como señala Alejandro Cerletti (2015), esa posición sigue siendo insuficiente por moderna o apegada a la idea lineal del progreso pedagógico en el ser humano, pues para Alejandro la pedagogía es más un laboratorio cruzado por la incertidumbre, donde el acontecimiento, como hecho indeterminado que es, va marcando el día a día desde los intereses y necesidades de las y los aprendientes. Eso no significa, como señala este autor, que no haya campo para la planificación ni para las finalidades, sino que ellas están atadas a la emergencia, a la insurgencia y a la transformación; es decir, el currículo emergente debería ir marcando el ritmo de los aprendizajes en una pedagogía verdaderamente liberadora.

Así las cosas, el acto de la educación es un acto azaroso en tanto no se sabe qué piensan ni cómo actuarán sus agentes. Según Freire (2005), debe ser un acto total y liberador mediante la pregunta. La cual une estas dos posibilidades críticas: la de Freire, como apuntamos, aún muy apegada a la modernidad, y la de Cerletti, un tanto más transmoderna. La pregunta va más allá de lo progresivo y lo lineal o esperable, propicia diálogo, intercambio, da lugar a lo emergente y a la toma de conciencia para la transformación de la realidad. La pregunta es un acto del lenguaje y la conciencia donde el sujeto educativo se apropia de la materialidad de la palabra, y desde esa historicidad construye con otros/ as su propia vida. Ya nadie tiene que hablar por los sujetos educativos ni en su lugar, dado que a partir de nuestras preguntas totales creamos nuestro criterio sin consumir respuestas definitivas de otros (Freire y Faundez, 2013). Para Freire (2003) la educación, al ser un acto dialógico, posee un carácter de intercambio donde "quien enseña aprende al enseñar y quien aprende, enseña al aprender" (p. 40).

Es necesario eliminar la falsa dicotomía docente versus estudiante para llegar a la educación liberadora. Freire propone, en sintonía con la pregunta, seguir métodos dialógicos como el de la problematización, donde nadie complete a nadie sino donde todos y todas nos eduquemos juntos/as, desde la emergencia de nuestras realidades (parafraseando a 
Cerletti, 2015). Con su propuesta dialógica, Freire (2003) hace un énfasis en la condición comunicativa de la Pedagogía, yendo más allá de su solo carácter transmisor. Ese diálogo problematizador y emergente es fundamental para enseñar filosofía y enseñar a filosofar, implica intercambio, preguntar o aún mejor hacer las preguntas que nos acontecen, que den sentido a nuestras vidas, que nos ayuden a repensar la realidad para luego poder transformarla.

Según Freire (2005) educar es humanizar y no hay humanización posible sin liberación, así como no hay liberación sin una transformación real de las condiciones de sometimiento. Así, enseñar filosofía de modo problematizador puede ir generando pensamiento crítico, autonomía y liberación del sujeto estudiante encadenado a prejuicios, estereotipos y estigmatizaciones propios de los imaginarios sociales, culturales y políticos de la sociedad que le rodea. Con la problematización desde la emergencia no se da nada por definitivo, se duda de todo y hasta de la duda misma, se ausculta toda certeza, se revisa lo aparentemente correcto o normal, se profundiza más allá de la superficie, de lo establecido como sentido último de las cosas. En suma, problematizar es un método filosófico-pedagógico para propiciar el encuentro, el diálogo, la búsqueda y construcción colectiva de certezas y la transformación social, pasando por la incertidumbre de la emergencia del otro/otra.

\section{Filosofar como comunidad liberadora}

Hoy en día ha habido una normalización de las prácticas de la destrucción y de la muerte dejando de lado la posible universalidad del criterio ético de la vida humana y no humana. Luego del genocidio de los pueblos originarios de América, de negros esclavos, de las mujeres consideradas brujas, del al-Ándalus, y del holocausto cometido por los Nazis, el Universal de la Vida dejó de serlo o quizás nunca lo fue. Aunque debemos reconocer que muchas experiencias de vida nos dan algunas luces de esperanza.

Hoy en día, igual y nuevamente, la vida se muestra en agonía, lo que parece no llamar la atención de casi nadie, pues esta es una categoría vaciada o líquida como diría Bauman (2004). Se trata de un gran "te pasa a ti, no es conmigo, yo sigo mi camino" que no solo individualiza las causas y los efectos, sino que sigue al individualismo metodológico 
propio de la razón instrumental creando justificaciones científicas que no dan cuenta de sus efectos éticos, sociales ni políticos.

La comunidad y la colaboración desaparecen desde este horizonte del pensamiento instrumentalista/utilitarista del estar en el mundo, pero el que no veamos los hilos que unen a unos con otros y a todos con la naturaleza no es suficiente condición para que la comunidad de la vida desaparezca, sino que simplemente queda oculta o invisibilizada. Es aquí donde la problematización como técnica didáctica desde el azar nos puede ayudar para dialogar con las y los estudiantes, y el resto de la comunidad educativa, sobre este fundamental tema, donde podemos partir de sus preguntas para filosofar al respecto con la intención de explorar los velos que se ciernen sobre la vida del ser humano actual, en tanto negación de posibilidad transformadora. En todo caso la filosofía, la que es crítica desde sus entrañas, nos puede acompañar para que la educación no pierda su sentido holónico o de la vida como criterio de totalidad y no se entregue a la producción instrumentalizada, pues nos acerca al cálculo de muerte. De este modo, la tarea de buscar lo oculto en lo aparente o lo que parece obvio e inobjetable es una labor propia de la filosofía, tal y cual lo expresa Cerletti, de alguna forma, en el epígrafe de este escrito.

Lo holónico no es un abstracto o sustancia metafísica, sino un principio material ético que se expresa mediante la inmediatez política a través de la acción, por ejemplo, contra o frente a los procesos de concentración de capital. Aquí es necesario realizar varias acotaciones. La característica de la inmediatez de las comunidades educativas, así como otras formas de comunidad, es su rica naturaleza social que supone otras formas de sociabilidad inmediata. Se trata de relaciones inmediatas, pero continuas. A diferencia de ello, la sociedad globalizada tiende a sujetarse mediante relaciones no inmediatas, pero con gran influencia en la vida de los seres humanos, los cuales quedan atrapados en no lugares, en relaciones banales indirectas, impersonales y lejanas. Tal es el caso de las redes sociales digitales o de los centros comerciales.

Por suerte, la educación dentro de un país, aunque sea controlada por un Estado y responda a un currículum oficial que busca ciudadanos obedientes, tiene sus manifestaciones en el espacio social local, en la inmediatez de las autopercepciones y en la comunicación cultural, lo cual demanda empatía por el/la otro/a. Esa cualidad psicológica es, precisamente, la base de la comunidad educativa, lo que impide su disolución; 
aunque, como ya se señaló, lamentablemente, los sujetos son lanzados al mundo de la globalización sin más, donde no les queda más que actuar primariamente como sujetos individuales frente a otros sujetos individuales en una desenfrenada competencia por la sobrevivencia, en la que posiblemente sin pretenderlo, producen su propia muerte.

Las comunidades campesinas, costeras y las indígenas suelen resistir a ese imaginario político de falsa cohesión atravesada por la libre competencia del mercado. Resisten mediante relaciones de inmediatez, premodernas o precapitalistas, manifestadas bajo lazos de solidaridad, que no suelen tener ligamen directo con las formas de la posesión individual del capital. Pero hasta esas comunidades son amenazadas por los efectos de tal globalización, las que suelen ser desterritorializadas al despropiarles sus tierras, al empobrecerlos y al precarizar sus formas de vida.

Sin que mitifiquemos las formas de vida campesinas e indígenas, antes de que estas sean destruidas por la globalización económica, lo cierto es que algunas relaciones de inmediatez siguen vigentes. Por ejemplo, en el campo no se deja morir a nadie: entre familiares y vecinos suelen realizar cadenas de producción e intercambio de productos para solventar las necesidades básicas, intercambio que emula el trueque practicado por nuestras comunidades indígenas desde tiempos inmemoriales. Se emplea una forma de comunicación directa, personal y cara a cara, pues esto ayuda a que, aunque existan grandes distorsiones en el mensaje, se suelan establecer lazos de fraternidad y protección comunitaria.

La condición de inmediatez comunitaria es menester a la hora de enseñar y aprender, y nada despreciable para la filosofía y el filosofar. Hacerlo desde esa condición nos acerca a la emergencia del otro/a, a su contextualidad en tanto sujetos educativos, favorece la horizontalización y puede ayudar a la descolonización de la misma filosofía, tal y cual hemos insistido sobre su posibilidad y necesidad en el presente libro, concretamente en el ensayo denominado La enseñanza de la filosofia desde nuestra realidad latinoamericana: el caso de la Universidad Nacional de Costa Rica, donde se nos dan pistas para filosofar desde nuestro acontecer. El cual es, ante todo un acto espontáneo, inabarcable e irreductible, lo que implica una didáctica igualmente flexible, sin extremos de planificación pues se puede desaprovechar el currículo emergente, aunque como señalan Cerletti y D'Odorico en el presente libro, sin planificación tampoco habría acontecimiento, pues este último desborda lo que se trae como hipótesis de trabajo. Baste decir por ahora 
que no se trata de despreciar el currículo establecido sino de aprovechar las particularidades que surjan en la problematización del mismo, para desde allí dar sentido a las vidas de los sujetos educativos mediante la dinamicidad que presenta el acontecimiento educativo.

Como se ha insistido, pues, educar no es solo aprender un hacer, y aún peor, aprenderlo de modo mecánico, bancario o por hábito. Aprender ha de ser una tarea compleja, crítica, problematizadora y transformadora, lo que implica superar las concepciones mecanicistas, autoritarias, controladoras y simplistas del aprendizaje del/de la otro/a, sobrepasar, a la vez, teorías psicologistas del aprendizaje que "se han centrado exclusivamente en las conductas que se desean manipular en el ser humano con el fin de alienar las identidades y obligar a las conciencias" (Bazán, 2008, p. 133).

\section{A modo de cierre}

Siguiendo lo expuesto aquí, si utilizamos a la problematización como una actitud más que como una técnica didáctica, como un espíritu de sabiduría sabiendo que no sabemos todo pero que podemos aprender algo, podríamos hacer frente a la educación tradicional que suele ser mecánica y verticalista, en la que reproducir es la tarea fundamental por lograr. Como se ha visto a lo largo del presente ensayo, la enseñanza y el aprendizaje como acto total inmediato, como acontecimiento problematizador, buscan crear, producir o construir, sin renunciar del todo a la transmisión. La cual se considera complementaria en tanto nos ayuda a aprender buenas prácticas dejadas por otras generaciones, aunque problematizándolas. Sin duda, esa propuesta holónica puede ser un gran aporte para revitalizar el espíritu crítico que debe poseer la enseñanza de la filosofía mediante el aprender a filosofar.

\section{Referencias}

Adorno, T. (1999). Educación para la emancipación. España: Morata. Althusser, L. (1988). Ideología y aparatos ideológicos del Estado. Argentina: Nueva Visión.

Bazán, D. (2008). El oficio del pedagogo. Aportes para la construcción de una práctica reflexiva en la escuela. Argentina: HomoSapiens. Bauman, Z. (2004). Modernidad líquida. Argentina: EFE. 
Butler, J. (1997). Mecanismos psíquicos del poder; teorías sobre la sujeción. España: Cátedra

Cerletti, A. (2015). Didáctica aleatoria de la filosofía, dialéctica del aprendizaje filosófico. En A. Cerletti y A. Couló (edit.), Didácticas de la filosofía Entre enseñar y aprender a filosofar (pp. 1532). Argentina: Novedades educativas.

Cerletti, A. (2016). Repetición, novedad y sujeto en la educación: un enfoque filosófico y político. Argentina: Serie del Estudiante.

Dussel, E. (2015). Filosofía del Sur: Descolonización y transmodernidad. México: Akal.

Freire, P. (2003). El Grito Manso. Argentina: Siglo XXI.

Freire, P. (2005). Pedagogía del Oprimido. Quincuagésima sexta edición. México: Siglo XXI.

Freire, P. y Faundez, A. (2013). Pedagogía de la pregunta: crítica a una educación basada en respuestas a preguntas inexistentes. Argentina: Siglo XXI.

Hegel, G. (2008). Fenomenología del espíritu. México: EFE.

Heidegger, M. (2012). El ser y el tiempo. Argentina: EFE.

Kant, I. (2012). Contestación a la pregunta: ¿qué es la ilustración? México: Taurus.

Lévinas, E. (2009). Descubriendo la existencia con Hursserl y Heidegger. España: Editorial Síntesis.

Marx, K. (1981). El Capital. Tomo I. Cuba: Editorial de Ciencias Sociales.

Marx, K. (2008). Contribución a la crítica de la economía política. Novena edición. México: Siglo XXI.

May, R. (2004). Ética y medio ambiente: hacia una ética sostenible. Costa Rica: DEI.

Rancière, J. (2003). El maestro ignorante. España: LAERTES

Singer, P. (1999). Liberación animal. España: Trotta.

Singer, P. (2003). Un solo mundo: la ética de la globalización. España: Paidós.

Skliar, C. (2007). La educación (que es) del otro: argumentos y desierto de argumentos pedagógicos. Argentina: Novedades Educativas.

Žižek, S. (2009). Sobre la violencia: seis reflexiones marginales. España: Paidós. 